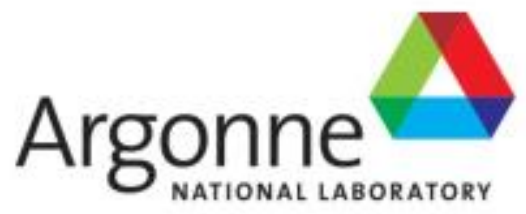

ANL-16/21

NATIONAL LABORATORY

\title{
MPAS Atmospheric Boundary Layer Simulation under Selected Stability Conditions: Evaluation Using the SWIFT Dataset
}

Environmental Science Division 


\begin{abstract}
About Argonne National Laboratory
Argonne is a U.S. Department of Energy laboratory managed by UChicago Argonne, LLC under contract DE-AC02-06CH11357. The Laboratory's main facility is outside Chicago, at 9700 South Cass Avenue, Argonne, Illinois 60439. For information about Argonne and its pioneering science and technology programs, see www, anl.gov.
\end{abstract}

\title{
DOCUMENT AVAILABILITY
}

Online Access: U.S. Department of Energy (DOE) reports produced after 1991 and a growing number of pre-1991 documents are available free via DOE's SciTech Connect (http:///unww.osti.gov/scitech/).

Reports not in digital format may be purchased by the public from the National Technical Information Service (NTIS):

U.S. Department of Commerce

National Technical Information Service

5301 Shawnee Rd

Alexandria, VA 22312

www.ntis.gov

Phone: (800) 553-NTIS (6847) or (703) 605-6000

Fax: (703) 605-6900

Email: orders@ntis.gov

Reports not in digital format are available to DOE and DOE contractors from the Office of Scientific and Technical Information (OSTI):

U.S. Department of Energy

Office of Scientific and Technical Information

P.O. Box 62

Oak Ridge, TN 37831-0062

www.osti.gov

Phone: (865) 576-8401

Fax: (865) $576-5728$

Email: reports@osti.gov

\section{Disclaimer}

This report was prepared as an account of work sponsored by an agency of the United States Government. Neither the United States Government nor any agency thereof, nor UChicago Argonne, LLC, nor any of their employees or officers, makes any warranty, express or implied, or assumes any legal liability or responsibility for the accuracy, completeness, or usefulness of any information, apparatus, product, or process disclosed, or represents that its use would not infringe privately owned rights. Reference herein to any specific commercial product, process, or service by trade name, trademark, manufacturer, or otherwise, does not necessarily constitute or imply its endorsement, recornmendation, or favoring by the United States Government or any agency thereof. The views and opinions of document authors expressed herein do not necessarily state or reflect those of the United States Govemment or any agency thereof, Argonne National Laboratory, or UChicago Argonne, LLC. 


\section{MPAS Atmospheric Boundary Layer Simulation under Selected Stability Conditions: Evaluation Using the SWIFT Dataset}

prepared by

V. Rao Kotamarthi and Yan Feng

Environmental Science Division, Argonne National Laboratory

prepared for

Mesoscale-to-Microscale Coupling Project, Wind and Water Program

Technology Office (WWPTO), EERE, DOE

October 12, 2016 



\section{CONTENTS}

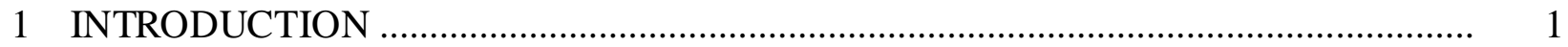

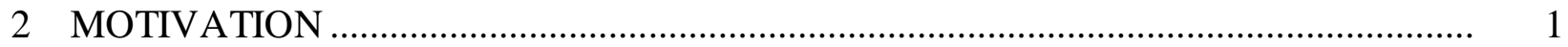

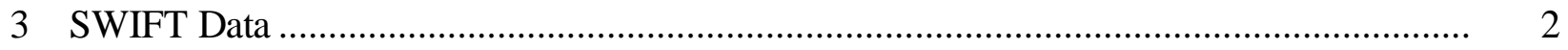

4 METHODOLOGY ..........................................................................................

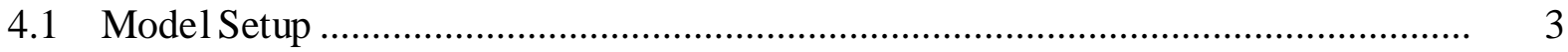

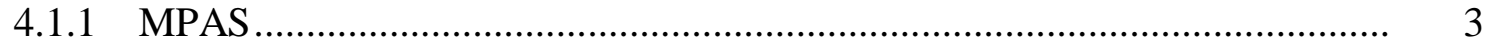

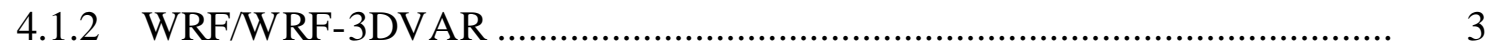

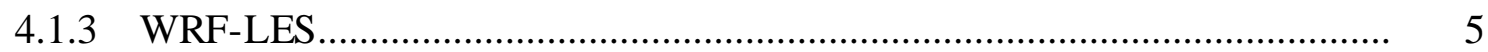

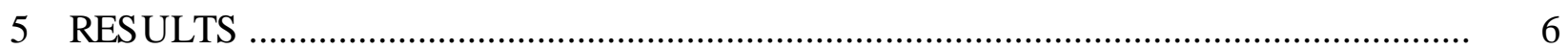

5.1 General Meteorological Conditions ......................................................................... 6

5.2 Wind Profiles for the Neutral Case ………………………....................................... 8

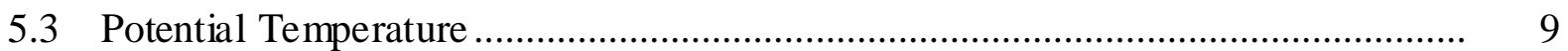

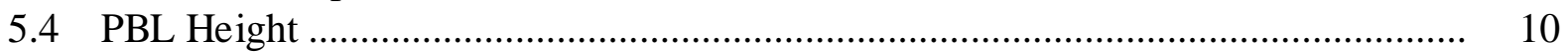

5.5 Surface Fluxes .................................................................................................... 11

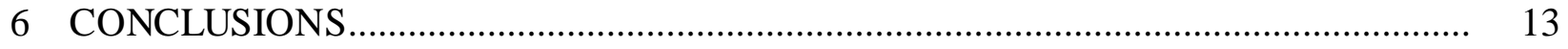

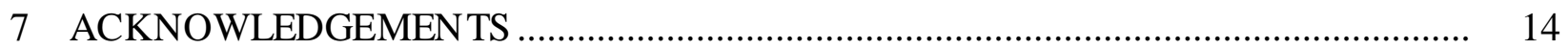

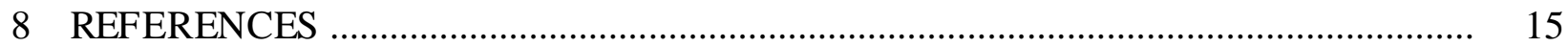

\section{FIGURES}

1 Scaled Wind Farm Technology site located in Lubbock, Texas. Configuration of a 200-m meteorological measurement tower at the site.

2 Simulated potential temperature profiles during the near-neutral conditions at approximately 00 to 1 a.m. UTC on August 17 at the SWIFT site in Texas.

$4 \quad$ The model domain used in WRF-3DVAR simualtions................................................. 4

5 The approximately $15-\mathrm{km}$ variable mesh generated for the MPAS resolution and the vertical resolution of the model.

$6 \quad$ Surface weather maps for the 17th and 18th August 2012.......................................... 7

$7 \quad$ Results from MPAS and WRF model simulations for August 17th at 7 p.m. ............... 7 


\section{FIGURES (Cont.)}

7 Simulated wind velocity profiles at various times between 12 a.m. UTC and 1 a.m. UTC, using the WRF model, WRF-3DVAR, and MPAS. ....................................... 8

8 Potential tempertaure profiles calculated with the WRF,WRF-3DVAR, and MPAS models for August 17th at the SWiFT site.

9 Wind and potential temperature profiles from WRF-LES at 12:30 a.m. UTC on August 18th.

10 PBL heights calculated by MPAS, WRF, and WRF-3DVAR.

11 Comparison of sensible heat flux from WRF 3D-VAR and MPAS for 12 p.m., 6 p.m., and 1 a.m. local time.

12 Comparison of latent heat flux from WRF 3D-VAR and MPAS for 12 p.m., 6 p.m., and 1 a.m. local time.

\section{TABLE}

1 WRF-LES simulations with different model configurations for the neutral case and convective case selected 


\section{INTRODUCTION}

Modeling the transition from mesoscale to microscale is necessary in order to model different processes that affect a wind farm and to develop forecasting tools that operate at the farm scale. The mesoscale-to-microscale coupling (MMC) project is an A2e (Atmosphere-toelectrons) coordinated activity for developing modeling capabilities at the wind farm scale. By moving the focus of the research from a single wind turbine to the collection of turbines that comprise a wind farm, A2e extends the range of spatial and timescales that need representation in a model from tens of meters to hundreds of kilometers and timescales from a few seconds to days (Bokharaie et al. 2016). In the atmosphere, these scales are represented by mesoscale-tomicroscale models. The modeling available at these scales has differed in its representation of various physical processes. The MMC group is responsible for evaluating existing models at these scales and recommending a set of options for coupling the mesoscale and microscale with the best-performing models. The group was organized in 2015 and will explore options for coupling strategies with real-world test problems in fiscal year (FY) 2017. The model of choice for this exercise is WRF (Weather Research Forecasting) for mesoscale and WRF-LES (Large Eddy Simulation) for microscale simulations. The MPAS (Model Prediction Across Scales) variable mesh model that can be continuously refined; it has dynamic core and physics options adopted from WRF, which offer an alternative platform for modeling the mesoscale.

\section{MOTIVATION}

Our primary interest in evaluating the MPAS model is the model's potential for providing a solution to some challenges researchers face when using WRF model for mesoscale simulation coupled with WRF-LES. The scale-down ratio of 1:3-recommended and widely used for WRF - achieves a large refinement in resolution by using a number of nested domains; however, it introduces numerical stability and convergence problems at each of the nesting boundaries (Gill and Pyle 2011). The newer dynamical core with unstructured mesh (MPAS) has been tested over the last few years (Skamarock et al., 2008), and a version of the MPAS model implemented with WRF physics is now available. The nest-down options provided by MPAS, which allow for a continuous grid refinement, are likely superior to those currently available with WRF. We initiated this work to evaluate the suitability of using MPAS to reach higher spatial resolutions $(<3 \mathrm{~km})$ for mesoscale phenomena. We investigate the capability of WRF and MPAS models under various configurations to simulate an observed neutral boundary layer case using data collected at the Scaled Wind Farm Technology (SWiFT) site. 


\section{SWIFT DATA}

The SWiFT site is located in Lubbock, Texas, at the Texas Tech National Wind Institute (Kelly and Ennis, 2016). The primary objective of the experimental site is to evaluate turbineturbine wake interactions. The facility hosts three reconfigured Vestas wind turbines with a hub height of $32.5 \mathrm{~m}$ and vertical rotor spans of $46 \mathrm{~m}$. A number of meteorological towers are close to these turbines, including two 58-m towers, a 200-m tower, and a 78-m tower. The data used in this study is from the 200-m tower analyzed and provided by Brandon Ennis of SNL (Sandia National Laboratory). The 200-m tower has three-dimensional (3D) sonic anemometers at 10 different locations at various heights on the tower. The two lowest-level measurements on the tower are made at 0.9 and $2.4 \mathrm{~m}$ (fig 1).
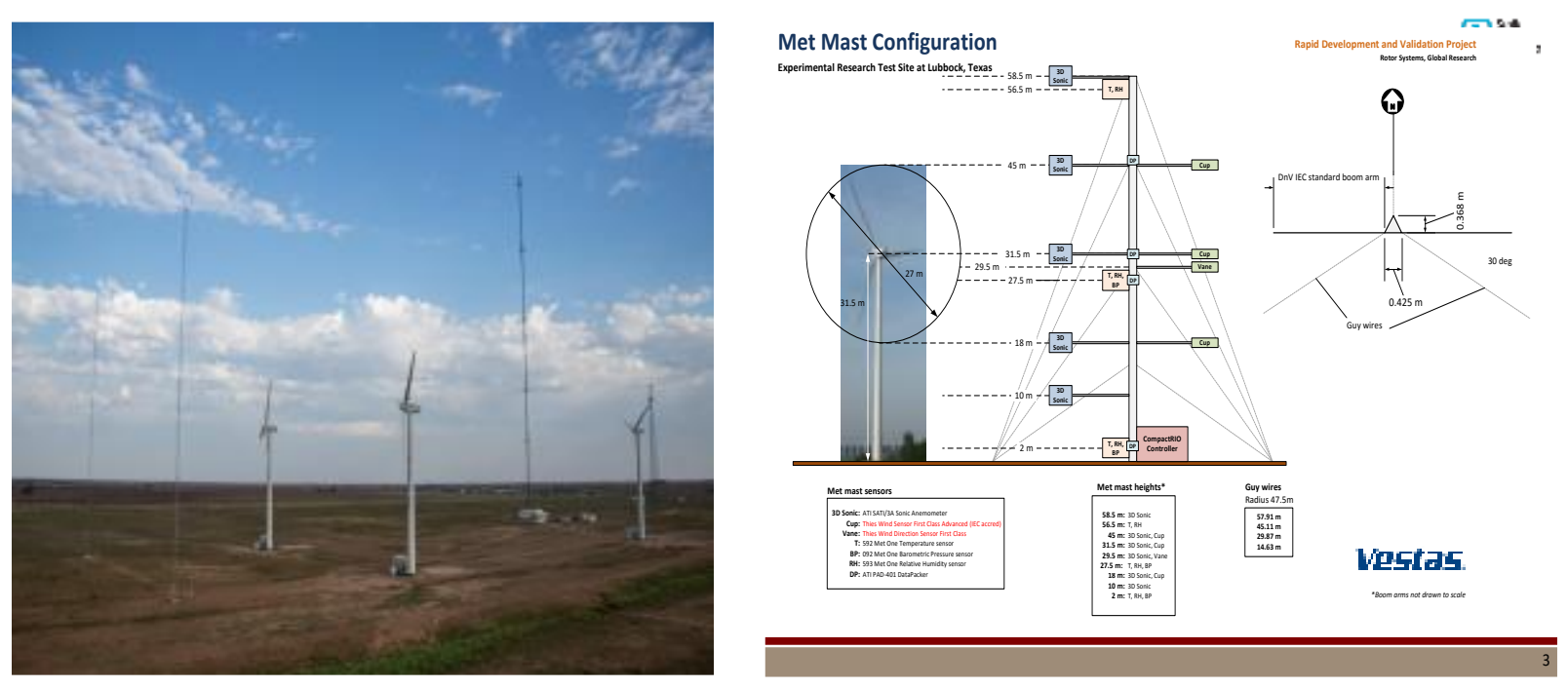

FIGURE 1 Scaled Wind Farm Technology (SWiFT) site located in Lubbock, Texas (left). Configuration of a 200-m me teorological me asurement tower at the site (right). The tower measures 3D wind ve locity at 10 differe nt heights (SAND2016-0216). 


\section{METHODOLOGY}

We performed simulations using WRF-3DVAR(3dimensional variational data assimilation), WRF-LES, and MPAS in August, 2011. This period was identified as experiencing neutral boundary layer conditions from approximately 00 hours Universal Time Coordinated (UTC) to 1 hours UTC (7 p.m. to 8 p.m. Central Daylight Time [CDT]) on August 17 and 18 of 2012. The WRF model simulations, which were performed by Caroline Draxl of National Renewable Energy Laboratory (NREL), capture this transition to neutral stability (Figure 2). We tested the ability of WRF-3DVAR, WRF-LES, and MPAS models to reproduce these conditions. The model setup, initial conditions, and boundary conditions used for each of these exercises is discussed next.

\subsection{WRF/WRF-3DVAR}

Observational nudging improves surface wind velocity and wind direction forecasts in mesoscale models (Gilliam and Pleim 2010). A preliminary assessment was performed to assess the impact of observational nudging on WRF forecasts. The evaluation used observational data from the Texas Mesonet (http://www.mesonet.ttu.edu) for the August 17th neutral case. A total of 54 stations were identified in the region surrounding the SWIFT site (Figure 3). For each of the neutral cases, we performed two sets of calculations. The first calculation was initialized with observations using the observational nudging code (the model WRFDA) to create an initial conditions field and modified boundary conditions at two starting times: $12 \mathrm{pm}$ the previous day and 00 hours on the day of the observed neutral case. The simulations that were observationally nudged 1 hour or less before the target time produce results that are closer to observations than those initialized with observational data 12 hours ahead of the time when the neutral conditions were observed. One conclusion would be that using observationally nudged simulations with new observations assimilated at frequencies with $1-\mathrm{hr}$

\subsection{MPAS}

The MPAS is a continuously refinable variable mesh model with dynamic core and physics options adopted from WRF (Skamarock and Klemp 2008). The model uses the Yonsei University (YSU) planetary boundary layer (PBL) scheme (Noh et al. 2003), the Noah land surface model (Chen and Dudhia 2001), Kain-Fritsch convection scheme (Kain 2004), and the Rapid Radiative Transfer Model-global (RRTMg; http://rtweb.aer.com) for radiative transfer. The surface layer is parameterized using Monin-Obhukov parameterizations. The MPAS model used here is global and has a spatial resolution of $15 \mathrm{~km}, 41$ vertical layers, and the model top is set at $30 \mathrm{~km}$ (Figure 4). The model initial conditions are set using NNRP (NCEP/NCAR Reanalysis Project) and the surface conditions (including the SSTs) are updated every 6 hours. The model was used to simulate for the entire month of August 2012. We compare the model simulations with a limited area simulation performed with WRF for a region that includes SWIFT at Texas Tech University in northwestern Texas 


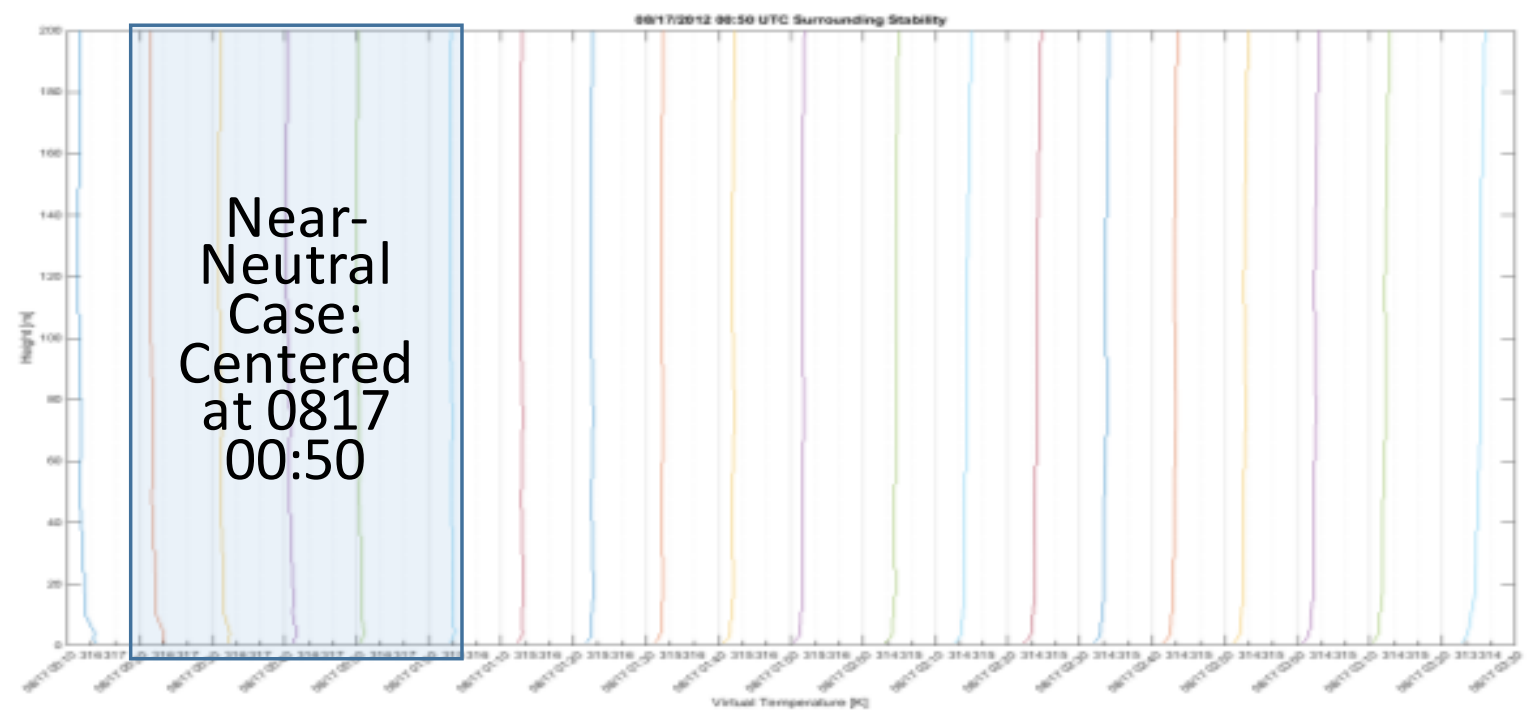

FIGURE 2 Simulate d pote ntial te mperature profiles during the ne ar-neutral conditions at approximate ly 00 to 01 hours UTC (7-8 p.m. CDT) on August 17 at the SWIFT site in Texas (courtesy of Caroline Draxl, NREL).
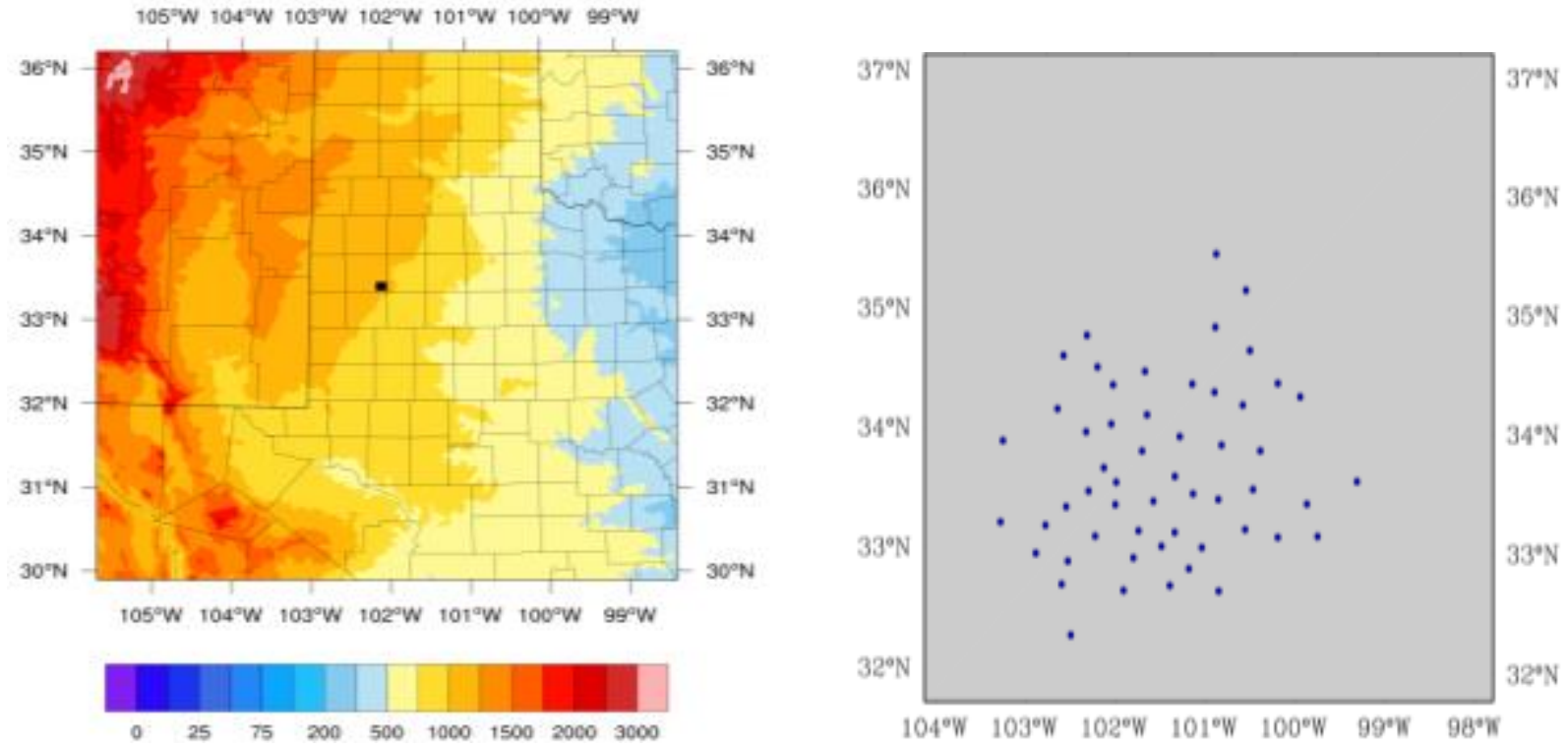

FIGURE 3 The model domain us ed in WRF-3DVAR simualtions. The black square approximately in the figure on the left shows the location of the SWiFT site and the colored contours are the terrain heights. The figure on the right covers a similar domain and shows the Me osnet stations used for as similation in the 3D-Var simulations. 
gaps will produce better surface wind fields. Continuously updated observational nudging using 3DVAR will have to be tested to obtain the most optimal observational nudging frequencies for this particular dataset. Calculations were also performed using the WRF model without the 3DVAR and with the same initial, boundary, and physics parameterizations.

\subsection{WRF-LES}

WRF-LES simulations were also performed for the neural boundary layer case during the late evening (0020-0220 UTC) of August 17, 2012, using WRF 3.6 in LES mode. The simulations were run over a domain of $2.4 \mathrm{~km} \times 2.4 \mathrm{~km} \times 2 \mathrm{~km}$, with a horizontal resolution of $25 \mathrm{~m}$ and a resolution of $7.5 \mathrm{~m}$ below $500 \mathrm{~m}$ in the vertical direction. The baseline case uses the Lilly SGS (subgrid scale) model (Lilly 1967) with a surface roughness (zo) of $0.05 \mathrm{~m}$. Model sensitivity to using the Smagorinsky SGS model (Smagorinsky 1963) and other model configurations were also performed for the neutral case. The idealized LES simulations were initialized with sounding profiles that approximated the tower observations at the SWIFT site. The wind components were initialized as geostrophic wind values. The initial temperature was specified to be consistent with potential temperature profiles of $\theta(z)=\theta_{B}+a(z)+a^{\prime}(z)$. Here, $\theta(z)$ $=\left[P_{0} / p(z)\right]^{0.286}$, where $P_{0}=1000 \mathrm{hPa}$ is a reference pressure, $\theta_{B}$ is a background constant value, $a(z)$ specifies an inversion of $500 \mathrm{~m}$ with a rate of $10 \mathrm{~K} / \mathrm{km}$, to prevent turbulence from reaching the model top, and $a^{\prime}(z)$ are small perturbations $\in[ \pm 0.25 K]$, drawn from a uniform distribution, and scaled as a decreasing cubic function of height from the surface up to specified height. These small perturbations are applied only to the initial condition to seed turbulence. Table 1 summarizes the WRF-LES simulations performed at Argonne.

\section{TABLE 1 WRF-LES simulations with diffe rent mode I configurations for the ne utral case $(N)$ and convective case $(C)$ selected}

\begin{tabular}{|c|c|c|c|c|c|c|c|c|}
\hline & $\begin{array}{l}\Delta \mathrm{L}_{\mathrm{x}} \\
\left(\Delta \mathrm{L}_{\mathrm{y}}\right) \\
(\mathrm{m})\end{array}$ & $\begin{array}{l}\Delta \mathrm{L}_{2} \\
(\mathrm{~m})\end{array}$ & SGS & $\begin{array}{l}\text { Adv. } \\
\text { Scheme } \\
\text { order }\end{array}$ & $\begin{array}{l}Q \\
\left(\mathrm{~m} \mathrm{~s}^{-1} \mathrm{~K}\right)\end{array}$ & $\begin{array}{l}\mathrm{T}_{\text {spimup }} \\
\text { (hr) }\end{array}$ & $\begin{array}{l}U_{g} \\
\left(\mathrm{~m} \mathrm{~s}^{-1}\right)\end{array}$ & $\begin{array}{l}Z_{0} \\
(m)\end{array}$ \\
\hline N1 & 25 & 7.5 & Lilly & High & 0 & 16 & 6.5 & 0.05 \\
\hline N2 & 25 & 7.5 & Lilly & High & 0 & 16 & 6.5 & 0.1 \\
\hline N3 & 25 & 7.5 & NBA-SR & High & 0 & 14 & 6.5 & 0.1 \\
\hline N4 & 25 & 7.5 & SMAG & High & 0 & 16 & 6.5 & 0.1 \\
\hline $\mathrm{C} 1$ & 30 & 10 & NBA-TKE & High & 0.4364 & 2 & 10 & 0.05 \\
\hline $\mathrm{C} 2$ & 30 & 10 & NBA-TKE & High & 0.35 & 2 & 10 & 0.05 \\
\hline $\mathrm{C} 3$ & 30 & 10 & NBA-SR & Low & 0.35 & 2 & 9 & 0.05 \\
\hline $\mathrm{C} 4$ & 20 & 20 & NBA-SR & Low & 0.35 & 2 & 9 & 0.05 \\
\hline
\end{tabular}



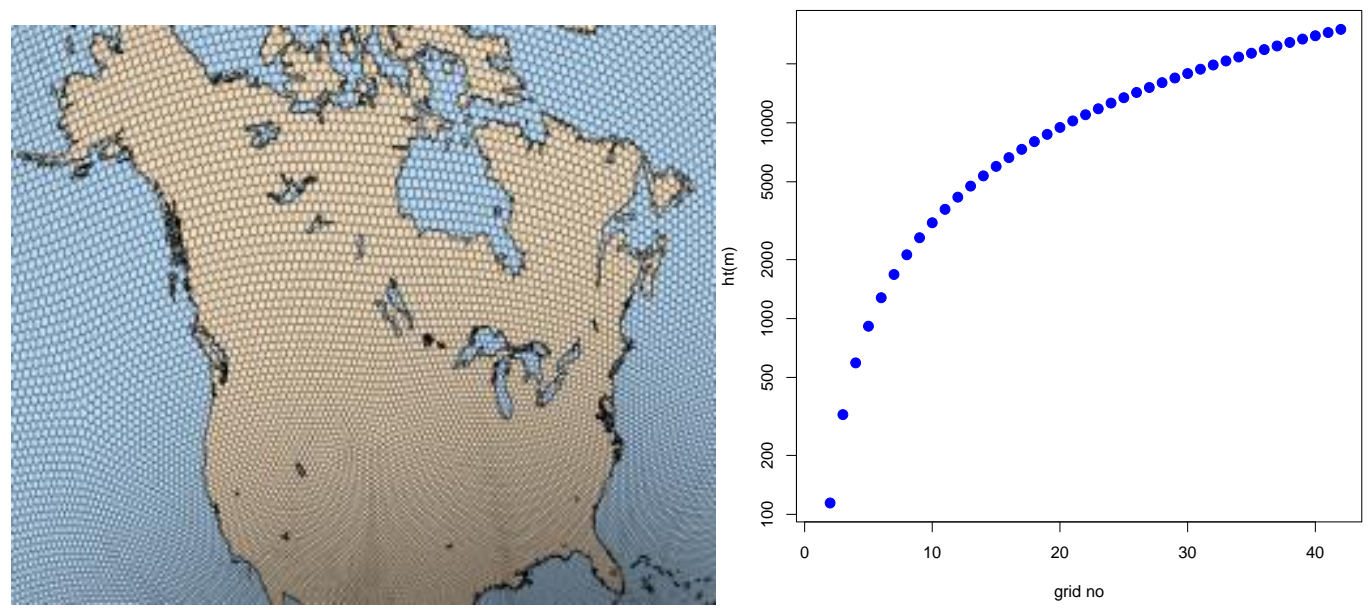

FIGURE 4 The approximately 15-km variable mesh generated for the MPAS resolution (left) and the vertical resolution of the model (right). The vertical resolution is approximate $150 \mathrm{~m}$ in the lower atmosphere.

\section{RESULTS}

\subsection{GENERAL METEOROLOGICAL CONDITIONS}

Figure 5 shows the meteorological conditions at the surface at 7 a.m. CDT on 17 th and the 18th days of August. A cold front was positioned to the west of the SWiFT site on the morningof the $17 \mathrm{th}$, and it and moved over the site by early morning the next day. To the east and in front of the cold front was a high-pressure system that moved out of the domain the following day. Another high-pressure system was located west of the site on both days, with its location moving closer to the site on the 18th. Figure 6 shows the results obtained from the WRF and MPAS models $5 \mathrm{~km}$ above the ground. The MPAS and WRF models had approximately the same wind velocities over most of the domain. The MPAS model located the high-pressure system farther to the east and south compared to the WRF model. The low-pressure region to the south and east of the SWiFT site (lower right corner of the domain) is not a prominent feature of the MPAS model, as compared to the WRF results. These features are similar to the conditions observe as shown in Figure 5. 

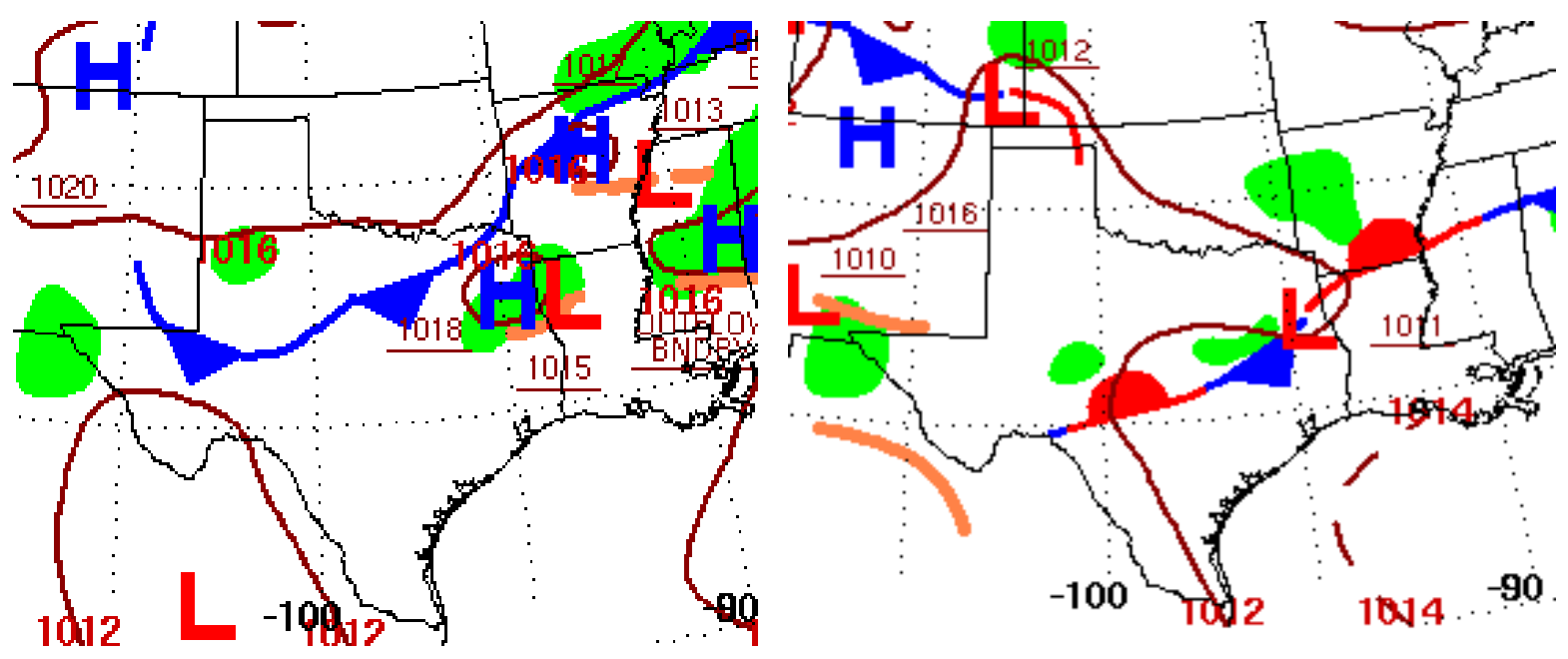

FIGURE 5 Surface we ather maps for the 17 th (le ft) and 18th (right) August 2012. The ne utral case we are exploring occurred between and 7 and 8 p.m. on the 17 th.

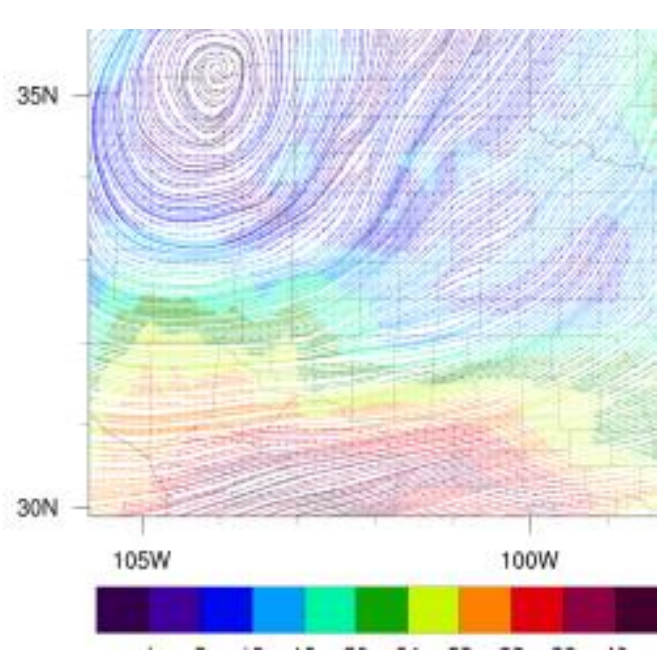

MPAS
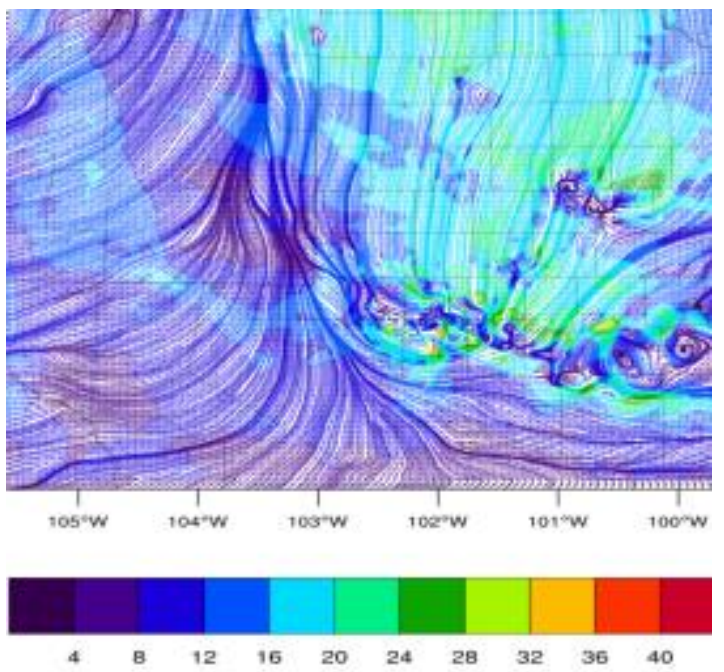

WRF

FIGURE 6 Results from MPAS and WRF model simulations for August 17 th at 7 p.m. The color coding gives the wind spe eds. The domains shown are approximately the same size and cover the SWiFT site. 


\subsection{WIND PROFILES FOR THE NEUTRAL CASE}

The model-simulated wind profiles were saved every 5 minutes for the entire simulation period with the WRF, WRF-3DVAR, and MPAS models at the SWiFT site. Figure 7 shows the results from these simulations. The WRF model underestimates the model wind velocities by a factor of 2 to 3 and the wind profiles start moving away from neutral conditions by 1 a.m. The WRF-3DVAR wind velocities are closer to the observed wind profile, and times closer to 1 A.M. UTC are closest to the observations. The profile is similar to observations and stays neutral near the surface for the entire time period. MPAS output was saved once every hour for the entire month of August and the figure 7( C) shows results from 12, 1, and 2 a.m. UTC. The MPAS model simulates the neutral profile; however, the model vertical resolution is coarse and there are only about six layers in the lower $200 \mathrm{~m}$ of the model. The model produces higher velocities than both WRF and WRF-3DVAR.

(A)

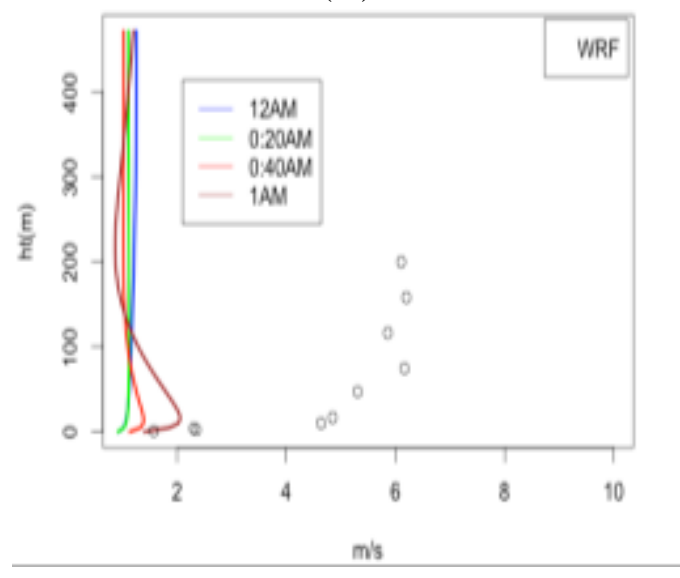

(C)

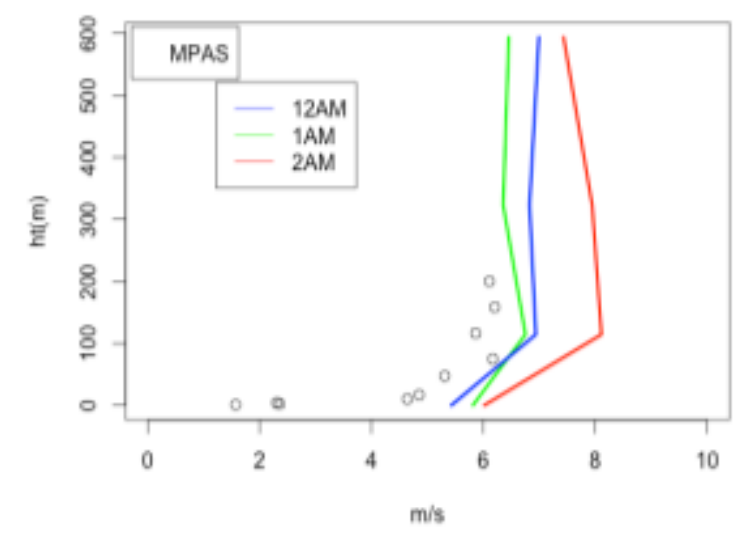

(B)

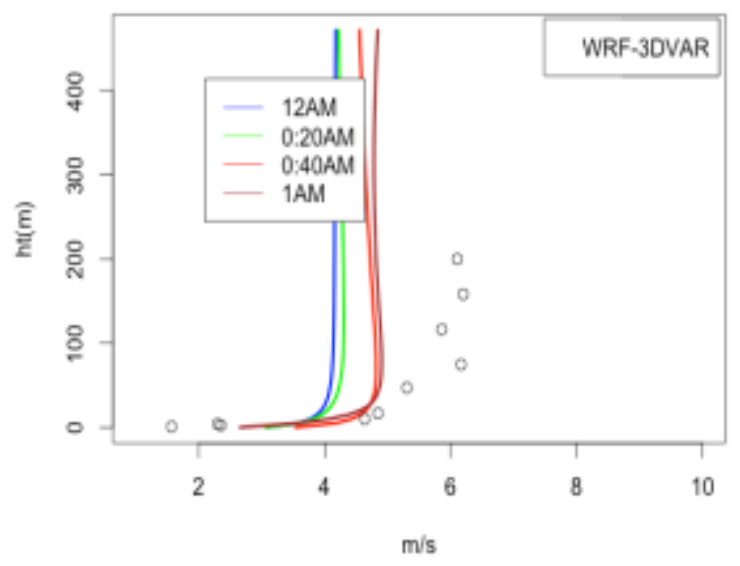

FIGURE 7 Simulated wind velocity profiles at various times between 12 a.m. UTC and 1 a.m. UTC, using the (A) WRF model, (B) WRF-3DVAR, and (C) MPAS. The circles shown are the me as ure ments from the 200-m tower at the SWiFT site. 


\subsection{POTENTIAL TEMPERATURE}

Figure 8 shows a similar comparison for the calculated potential temperatures from the three models. The WRF model estimates higher potential temperature than observed by approximately 1 degree, and the WRF-3DVAR model underestimates the potential temperature by more than a degree. The MPAS model results at $1 \mathrm{a} . \mathrm{m}$. are approximately the same as observations at 1 a.m. UTC at the surface, but lower at higher altitude. The WRF-3DVAR shows temperature profiles that are closer to the neutral case at the surface, and the WRF output indicates a transition to an unsteady state at the surface by 1 a.m. UTC. The MPAS temperature profiles at 12 and 1 a.m. indicate neutral conditions.

(A)

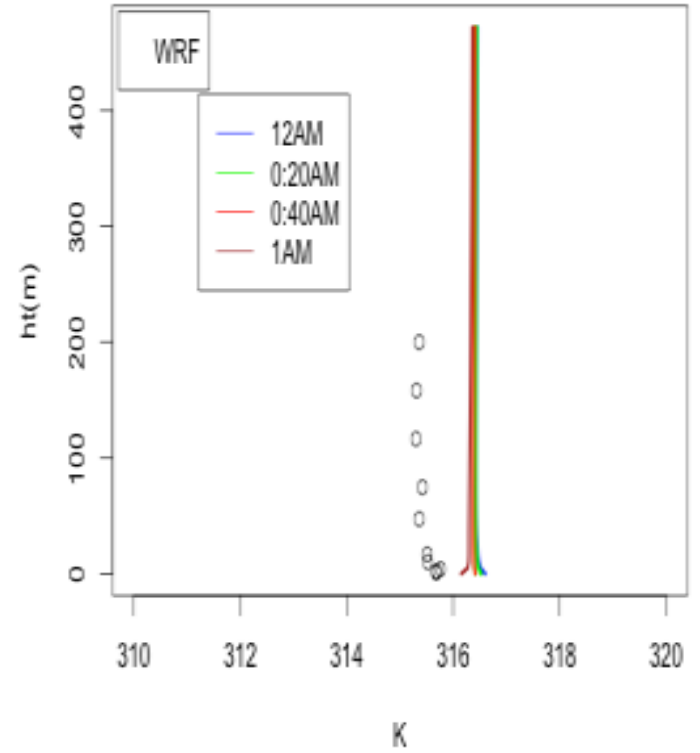

(C)

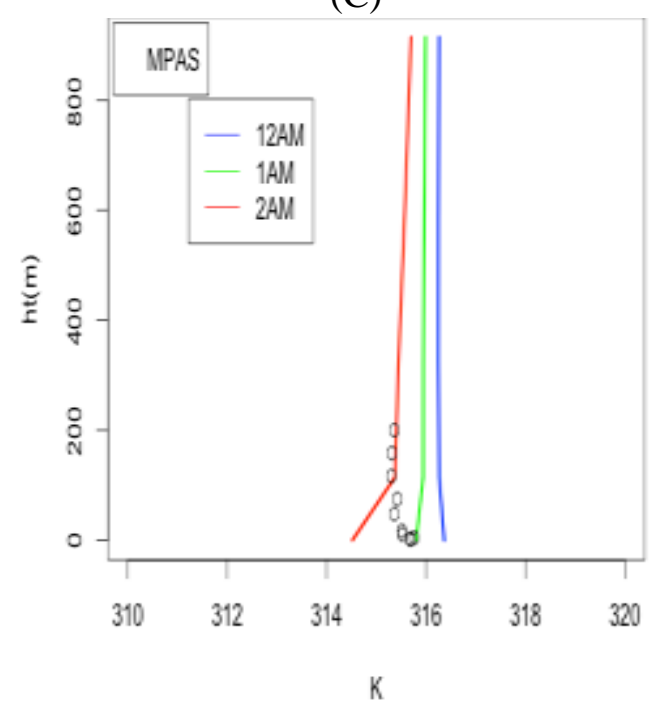

(B)

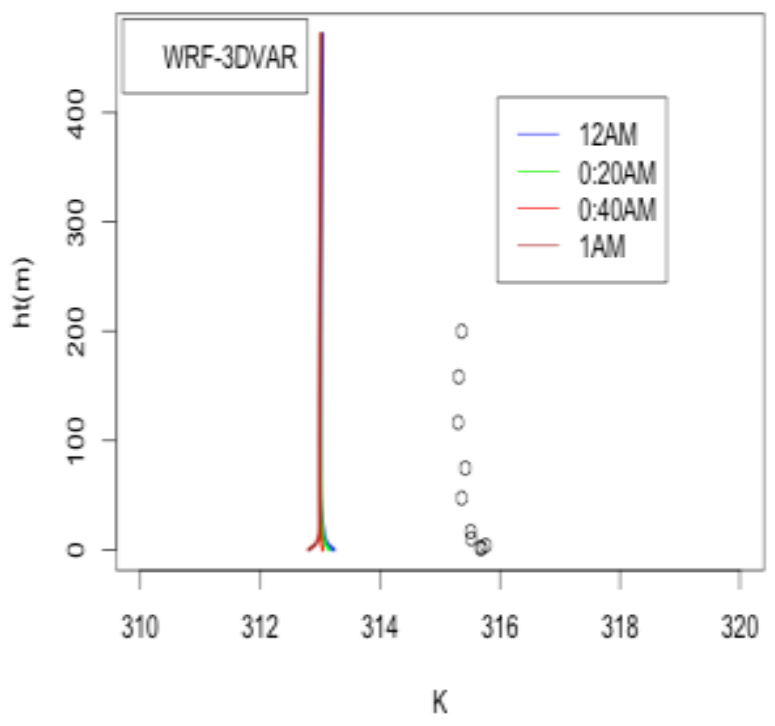

FIGURE 8 Potential te mpertaure profiles calculate d with the (A) WRF,(B) WRF-3DVAR, and (C) MPAS models for August 17th at the SWiFT site. The open circles are observed potential te mpe ratures from a 200-m tower at the site. 
Results from the WRF-LES are shown in Figure 9. The model is initialized with the observed temperature at the surface and geostropic forcing estimated from the observations at the tower. After 16-hour simulations, the boundary layer turbulence is fully spun up, reaching a nearly steady state for the baseline neutral case, as identified by the occurrence of the first maximum in horizontal velocity at $80 \mathrm{~m}$ above the surface. The model simulates both the temperature and wind profiles with greater accuracy, although the potential temperature estimated is slightly higher than observed and is similar to the WRF model.

\subsection{PBL HEIGHT}

The PBL heights calculated from the WRF, WRF-3DVAR, and MPAS models are shown in Figure 10. The PBL height estimated by the MPAS model is similar to that of the WRF model; it also produces a higher peak than WRF-3DVAR model and a smaller peak than that of the WRF model. The peak PBL heights produced by the WRF and MPAS models are similar at approximately the same time ( $20 \mathrm{hr}$ UTC $\sim 2 \mathrm{p} . \mathrm{m}$. CDT). The WRF-3DVAR PBL height is lower and appears an hour later than in the WRF and MPAS models. Some of the differences between the MPAS and WRF models can be explained by the differences in model spatial resolution in both in the vertical and the horizontal. Although the MPAS model is global in scope and was initialized on August 1st (with SST updates every 6 hours), the model compares favorably with WRF. It should also be noted that all three models use the same PBL scheme and other relevant physical parameterizations.
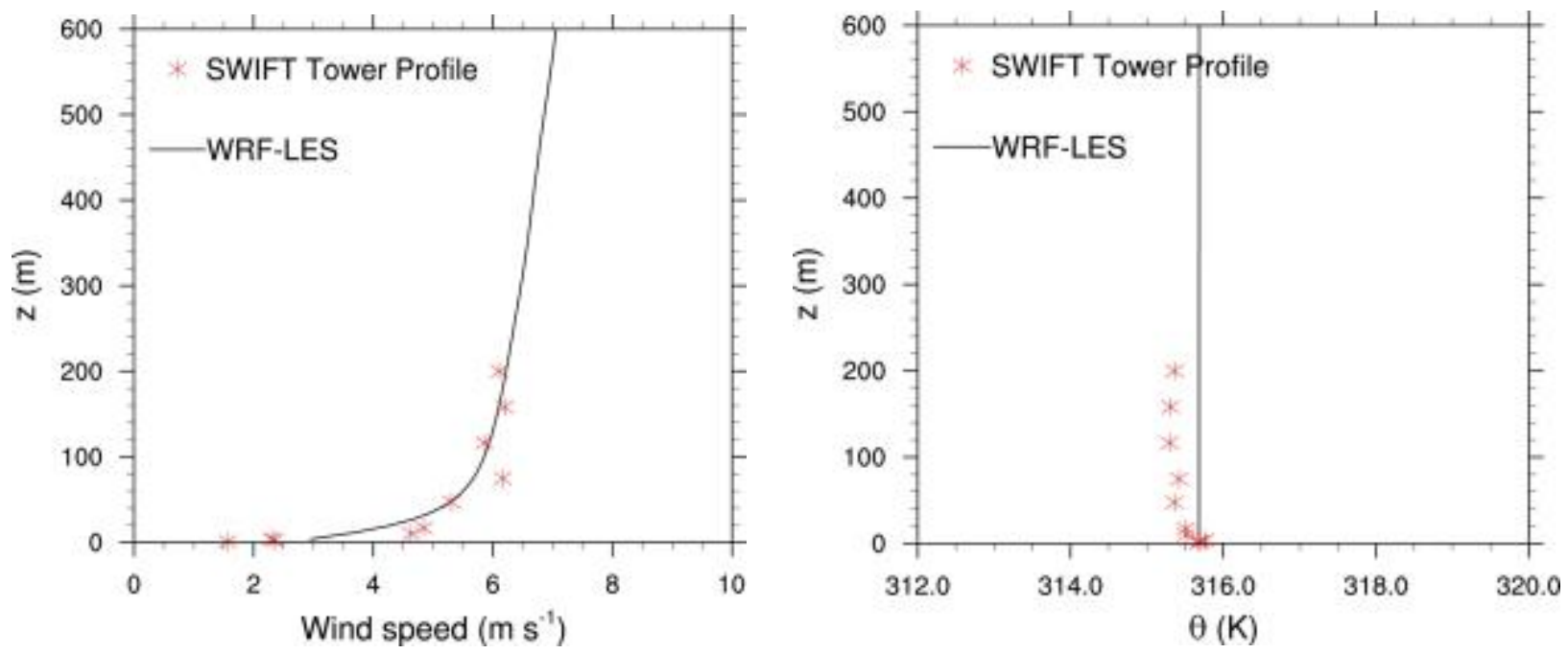

FIGURE 9 Wind and potential te mpe rature profiles from WRF-LES at 12:30 a.m. UTC on August 18th. 


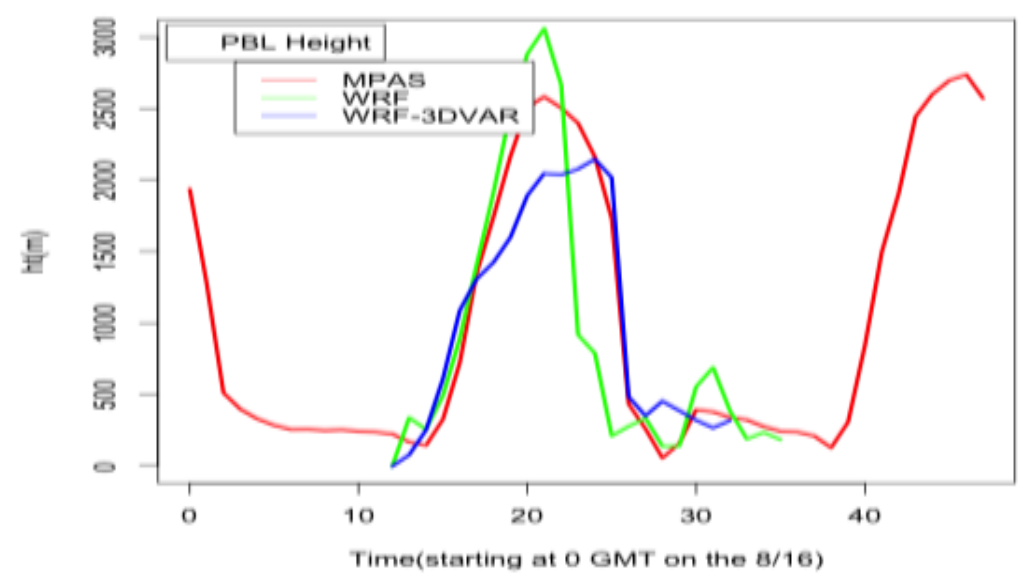

FIGURE 10 PBL heights calculated by MPAS (red line), WRF (green line), and WRF-3DVAR (blue line). Results are shown from 0 hrs UTC on the 16th to $0 \mathrm{hr}$ on the 19th of August.

\subsection{SURFACE FLUXES}

We also compared surface sensible heat flux calculated by the three different models over this region. Figure 11 shows the heat flux calculated in WRF-3DVAR (top row) and MPAS (bottom row). The WRF model calculates lower sensible heat flux for 12 p.m. and at 6 p.m. over the upper western quadrant of the model compared to MPAS. This could be related to the location of clouds in the model around the cold front and location of the high pressure over the west that was discussed in section 5.4 Although the eastern and southern halves of the domain are similar, the MPAS model estimates higher sensible heat fluxes over a larger domain in the south than the WRF-3DVAR does. Compared to the MPAS model, the location of the lowpressure system and the movement of the cold front and cloud cover in the lower eastern corner in the WRF and WRF-3DVAR models (which does not show the low pressure system in the lower part of the domain) could explain the differences. Both models show nearly zero sensible heat fluxes at night, as expected.

Comparison of latent heat fluxes leads to similar conclusions as shown in Figure 12. The higher latent fluxes in the WRF-3DVAR correspond to clouds/precipitation and overlap the regions with low sensible heat fluxes in Figure 11. The region around the location of the front in the lower eastern portion of the domain leads to precipitation and latent heat fluxes that are not captured by the MPAS model. This region is still experiencing enhanced latent fluxes later in the night that is absent in MPAS model. It is likely that the spatial resolution of MPAS model compared to the WRF contributes to lower amounts of clouds/precipitation in the model as compared to WRF 


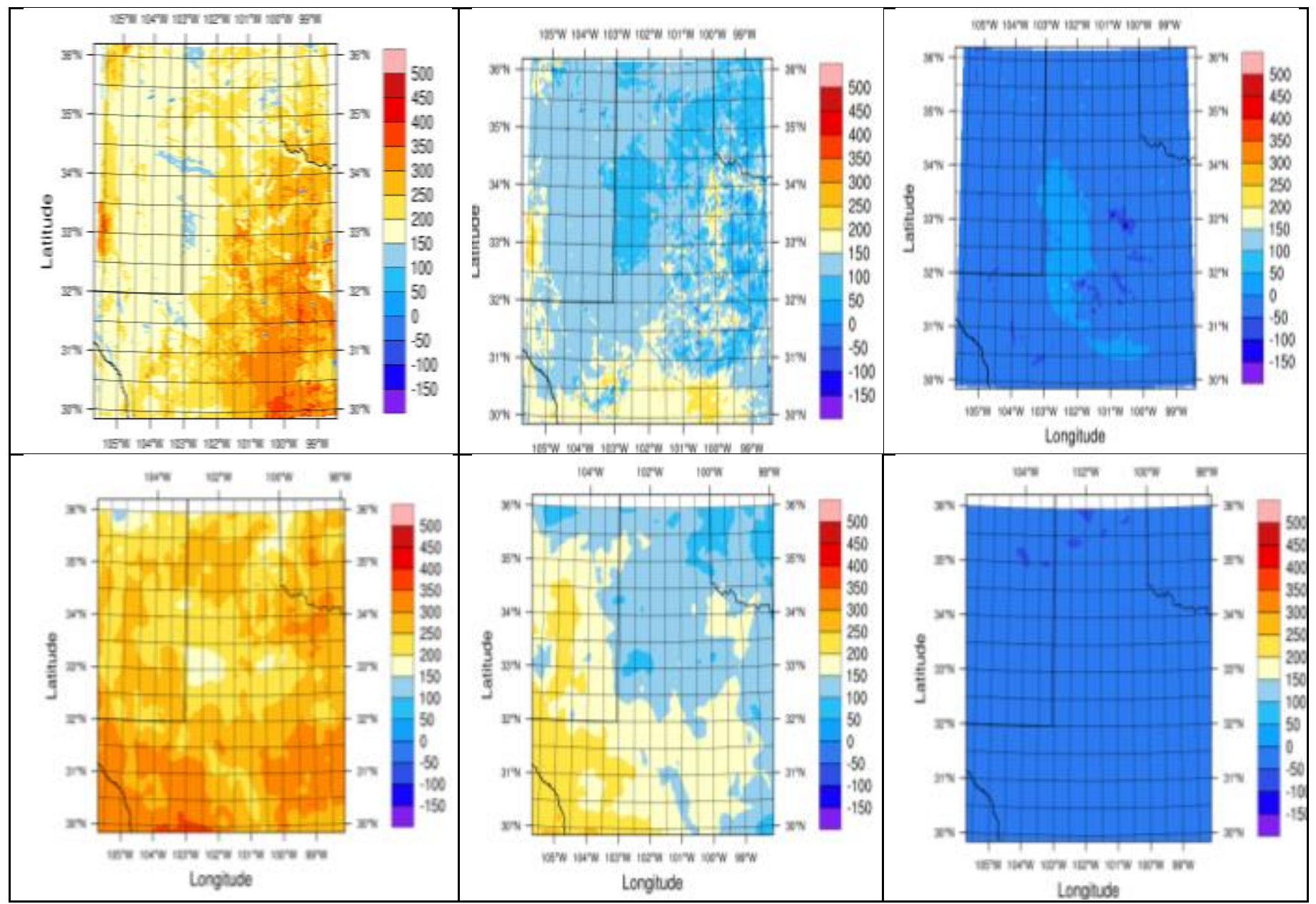

FIGURE 11 Comparison of sensible heat flux (in $\mathrm{W} \mathrm{m}^{-2}$ ) from WRF 3D-VAR (top row) and MPAS (bottom row) for 12 p.m. (left), 6 p.m. (middle), and 1 a.m. (right) local time 


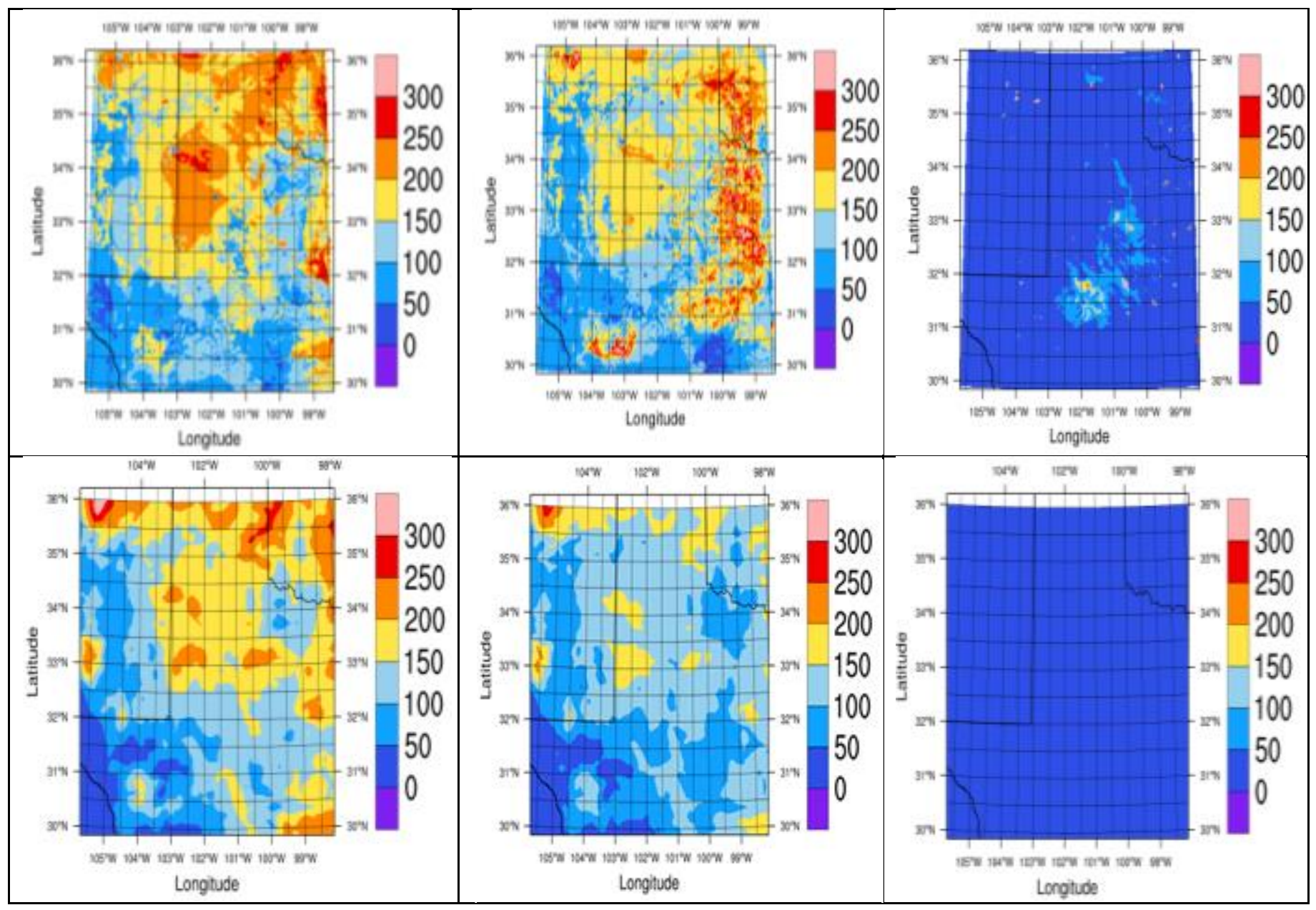

FIGURE 12 Comparis on of latent heat flux (in $\mathrm{W} \mathrm{m}^{-2}$ ) from WRF 3D-VAR (top row) and MPAS (bottom row) for 12 p.m. (le ft), 6 p.m. (middle), and 1 a.m. (right) local time.

\section{CONCLUSIONS}

We conducted a study to evaluate the performance of MPAS compared to WRF and WRF-3DVAR for a neutral stability case observed during the night of August 17th, 2012, at the SWiFT site in central Texas. Observations of temperature profiles and wind speeds made from a 200-m tower were used for the model evaluations. From these calculations we have shown that (a) surface heat fluxes calculated by WRF and MPAS are similar for the selected neutral case; (b) boundary-layer vertical profiles of wind speed calculated for the neutral case with MPAS were similar to the WRF meso-scale models; (c) WRF observationally nudged wind profiles with initialization the hour before the event produced the best comparison to the observed winds; (d) potential temperature profiles for all three cases show a neutral profile at the time when the observations were made; (e) WRF 3D-VAR and LES produced the closest reproduction of the 
observations; and (f) the PBL heights calculated by the three models differ by several hundred meters during the daytime but show similar diurnal transitions.

A thorough evaluation of the physical drivers behind these differences is beyond the scope of this report. However, we can conclude that higher vertical resolution in the MPAS model could alleviate some of the observed differences. Other challenges in using MPAS were the data volumes from the MPAS model at spatial resolution of $15 \mathrm{~km}$ and higher. At $15 \mathrm{~km}$ spatial resolution, the model produces more the $500 \mathrm{~GB}$ of output per calendar day of model simulations, when saved once every hour. Very few plotting and analysis tools are useful for handling this amount of output; we will need parallel processing tools (e.g., Paraview), which poses a challenge in terms of obtaining the computational/visualization resources and the effort needed for analysis. Developing a regional version of MPAS and better visualization and analysis tools in the model's native coordinates will be required to fully utilize the model for the MMC project.

\section{ACKNOWLEDGEMENTS}

This project was funded by the U.S. Department of Energy (DOE) Energy Efficiency and Renewable Energy (EERE) WETO to Argonne under contract through DOE contract DE-AC0206CH11357. The computational resources were provided by the Argonne Leadership Computing Facility and the National Energy Research Scientific Computing Center. Both are supported by DOE. We gratefully acknowledge the MMC team for providing input and some of the figures used in the report. 


\section{REFERENCES}

Bokharaie, V.S., P. Bauwererts, and J. Meyers, 2016, "Wind-farm layout optimization using a hubrid Jensen-LES approach," Wind Engineering Science and Discussion.

Chen, F., and J. Dudhia, 2001, "Coupling and advanced land surface hydrology model with the Penn State-NCAR MM5 modeling system. Part I: Model implementation and sensitivity," Mon. Weather Rev. 129:569- 585.

Kelly, C.L. and B. L. Ennis, SWiFT Site Atmospheric Characterization, SANDIA Report, Albuquerque, NM, SAND2016-0216,2016

Gill, D., and M. Pyle, 2011, "Nesting in WRF." Available at http://www2.mmm. ucar.edu/wrf/users/tutorial/201107/WRFNesting.ppt.pdf

Gilliam, Robert C., and Jonathan E. Pleim. "Performance assessment of new land surface and planetary boundary layer physics in the WRF-ARW." Journal of Applied Meteorology and Climatology 49.4 (2010): 760-774.

Kain, J.S., 2004, "The Kain -Fritsch convective parameterization: An update," J. Appl. Meteorol. 43:170-181.

Lilly, D. K. The representation of small scale turbulence in numerical simulation experiments. In IBM Scientific Computing Symposium on environmental sciences, pages 195-210, Yorktown heights, 1967.

Noh, Y., W.G. Cheon, S.-Y.Hong, and S. Raasch, 2003, "Improvement of the K-profile model for the planetary boundary layer based on large eddy simulation data," Boundary Layer Meteorology 107:401- 427.

Skamarock, W.C., and J.B. Klemp, 2008, "A time-split nonhydrostatic atmospheric model for weather research and forecasting applications," Journal of Computational Physics 227.7:34653485 .

Smagorinsky, Joseph. "General circulation experiments with the primitive equations: I. the basic experiment*." Monthly weather review 91.3 (1963): 99-164. 


\section{Argonne}

\section{Environmental Science Division}

Argonne National Laboratory

9700 South Cass Avenue, Bldg. 240

Argonne, IL 60439-4854

www.anl.gov 